\title{
Tradeoff between the Output Voltage Deviation and Recovery Time of Boost Converters
}

\author{
Junjie $\mathrm{Ge}^{\dagger}$, Liqiang Yuan ${ }^{*}$, Zhengming Zhao*, Ting Lu*, Fanbo He*, and Gaohui Feng* \\ ${ }^{\dagger *}$ State Key Laboratory of Power System, Department of Electrical Engineering, Tsinghua University, Beijing, China
}

\begin{abstract}
The time-optimal control for boost converters can achieve the minimum recovery time. However, their output voltage deviation is quite large. Since the minimum output voltage deviation and minimum recovery time cannot be obtained at the same time, a novel energy control is proposed to achieve a superior tradeoff between them in this paper. The peak value of the inductor current can be decreased as well. Its control parameter is easy to choose. When compared with the conventional control methods, the proposed control shows a better dynamic performance. Experimental results, which are in agreement with the theoretical analysis, are provided to verify the proposed control method.
\end{abstract}

Key words: Boost converters, Energy control, Output voltage deviation, Recovery time, Tradeoff

\section{INTRODUCTION}

Various control schemes have been developed to enhance the regulation performance of DC-DC converters over the past few decades. Since good dynamic performance has been emphasized, some time-optimal control methods have been proposed. Boundary control, which is a geometric based control method [1], [2], is a typical example of these control methods. There are a variety of studies on different switching surfaces, e.g., first-order and second-order switching surfaces, which can improve the dynamic performance [3]-[5]. Furthermore, minimum-time transient recovery during sudden load changes can be achieved by using natural switching surfaces [6], [7]. Some other time optimal controls can obtain the same effect [8]-[10]. Most of them can aslo achieve the minimum recovery time.

For buck converters, both the minimum output voltage deviation and the minimum recovery time can be achieved at the same time. Unfortunately, this is impossible with boost converters. The smaller the output voltage deviation, the smaller the capacitance can be. Therefore, a small voltage deviation is important in reducing the cost and volume of electrolytic capacitors, which is the weakest link in power

Manuscript received Sep. 29, 2014; accepted Nov. 22, 2014

Recommended for publication by Associate Editor Honnyong Cha.

${ }^{\dagger}$ Corresponding Author: gejunjie1359@163.com

Tel: +86-10-6277-3237, Fax: +86-10-6279-4915, Tsinghua University

*State Key Laboratory of Power System, Department of Electrical

Engineering, Tsinghua University, China electronic circuits. Augmented DC-DC converters can substantially reduce or eliminate output voltage deviations [11], [12]. However, additional circuits, which increase the cost and complexity of the control, are needed. [13] and [14] propose constrained control which can limit the inductor peak current. However, this is only for buck converters and the voltage deviation during sudden load changes has not been analyzed.

In addition, boost converters are non-minimum phase systems. As a result, conventional linear control methods are not able to achieve very good performance. Energy-based controls are nonlinear control techniques that are based on the concept of energy [15]. They use the measured or estimated energy in the inductors or capacitors of converters to obtain simple control structures. Lyapunov-based control employs the Lyapunov energy function to derive a linear control law with asymptotic stability [16]-[18]. Passivity-based control relies on the assumption that the system is made up of energy-transforming blocks. By adding damping and modifying the dissipation structure, which greatly affects the dynamics and stability, it can modify the system energy to achieve desired behavior [19]-[23]. Similarly, Hamiltonian control and dissipativity-based control rely on the energy-balancing principle or energy storage functions as well [24], [25].

Since the minimum output voltage deviation and the minimum recovery time cannot be achieved at the same time for boost converters, a good tradeoff between them is valuable. A novel high-order energy control, which considers the total 


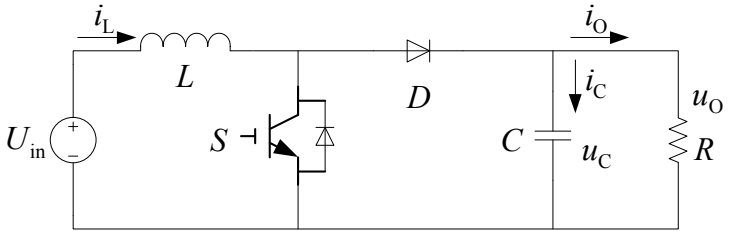

Fig. 1. Configuration of boost converters.

energy in the inductor and capacitor, is proposed in this paper. Unlike the conventional energy-based controls mentioned above, the proposed control method directly modifies the energy storage in the circuit. The order of its corresponding Lyapunov energy function is higher as well. Actually, the realization of the proposed control looks similar to the sliding-mode control and the synergetic control, which force the system to operate on a desired control manifold [26]-[30]. From the viewpoint of the sliding-mode control, it has an energy-based nonlinear sliding trajectory. Since its switching frequency is constant, it is more like the synergetic control. However, from the viewpoint of the synergetic control, its macro-variable is a high-order nonlinear function as well. Therefore, the proposed control can achieve a better dynamic performance, i.e., reduce the output voltage deviation in less time. Moreover, its control parameters are easier to choose. Experimental results are provided to verify the theoretical analysis.

\section{OUTPUT VOLTAGE DEVIATION AND RECOVERY TIME OF BOOST CONVERTERS}

The classic configuration of boost converters is shown in Fig. 1, where $L$ is the inductor, $C$ is the capacitor, $S$ is the switch, $D$ is the diode, $R$ is the load resistance, $U_{\text {in }}$ is the input supply voltage, $i_{\mathrm{L}}$ is the inductor current, $i_{\mathrm{C}}$ is the capacitor current, $u_{\mathrm{C}}$ is the capacitor voltage, i.e., output voltage $u_{\mathrm{O}}$, and $i_{\mathrm{O}}$ is the output current.

For buck converters, both the minimum output voltage deviation and the minimum recovery time can be achieved at the same time by employing the time-optimal control [10]. However, this is impossible for the boost converters in Fig. 1.

The waveforms of the boost converter with the time-optimal control are shown in Fig. 2. When the output power $p_{\text {out }}$ suddenly increases at $t_{0}, i_{\mathrm{L}}$ will be made to increase. The input power $p_{\text {in }}$ is equal to $p_{\text {out }}$ at $t_{1}$. However, $u_{\mathrm{C}}$ will keep decreasing until $t_{2}$ since an increase of $i_{\mathrm{L}}$ requires more energy. Then the minimum recovery time $t_{3}-t_{0}$ can be achieved. Nevertheless, the output voltage deviation is not the minimum. If $i_{\mathrm{L}}$ stops increasing before $t_{2}, u_{\mathrm{C}}$ will stop decreasing. The output voltage deviation can be smaller, but the recovery time will be longer.

As shown in Fig. 3, the output power is larger than the input power during $t_{0} \sim t_{1}$, and the input power is larger than the output power during $t_{1} \sim t_{3}$. It is worth pointing out that the energy changes $E_{1}$ and $E_{2}$ in these two periods have constant differences. The smaller the maximum input power, the longer the recovery time and the smaller the output voltage deviation.

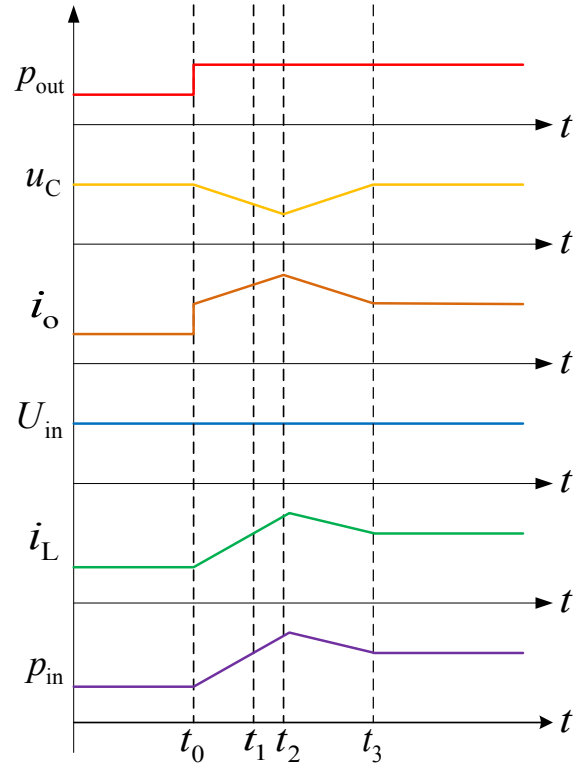

Fig. 2. Waveforms of time-optimal control.

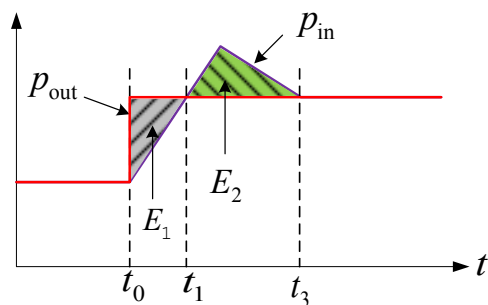

Fig. 3. Energy changes.

\section{NOVEL ENERGY CONTROL FOR TRADEOFF}

Since the minimum output voltage deviation and the minimum recovery time cannot be achieved at the same time for a boost converter, a good tradeoff between them is valuable. A novel high-order energy control is proposed to achieve a better tradeoff.

The energy changes of the boost converter are the energy changes of the inductor and capacitor in the circuit. The total energy in the inductor and the capacitor is:

$$
E_{\mathrm{LC}}=\frac{1}{2} C u_{\mathrm{O}}^{2}+\frac{1}{2} L i_{\mathrm{L}}^{2}
$$

When the target output voltage and inductor current are $u_{\mathrm{O}_{-}}$ and $i_{\mathrm{L}_{-} \mathrm{r}}$, the target energy is:

$$
E_{\mathrm{LC} \_\mathrm{r}_{\mathrm{r}}}=\frac{1}{2} C u_{\mathrm{O}_{-} \mathrm{r}}^{2}+\frac{1}{2} L i_{\mathrm{L}_{-} \mathrm{r}}^{2}
$$

The energy in the circuit can be modified to approach the target energy step by step if:

$$
L i_{\mathrm{L}}^{2}+k C u_{\mathrm{O}}^{2}=L i_{\mathrm{L}_{-} \mathrm{r}}^{2}+k C u_{\mathrm{O}_{-} \mathrm{r}}^{2}
$$

where $k$ is a control parameter and $0<k<1$.

When $u_{\mathrm{O}}<u_{\mathrm{O}_{-} \mathrm{r}}$, from (3), the energy is:

$$
E_{\mathrm{LC}}=\frac{1}{2} L i_{\mathrm{L}_{-} \mathrm{r}}^{2}+\frac{1}{2} C u_{\mathrm{O}_{-} \mathrm{r}}^{2}-\frac{1}{2}(1-k) C\left(u_{\mathrm{O}_{-} \mathrm{r}}^{2}-u_{\mathrm{O}}^{2}\right)<E_{\mathrm{LC}_{-}}
$$




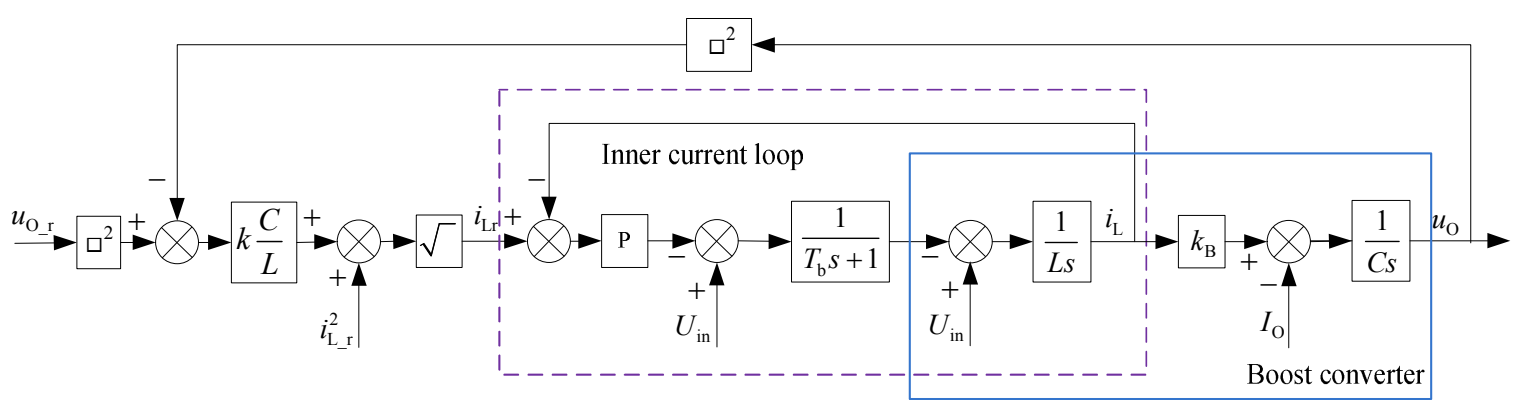

Fig. 4. Control diagram.

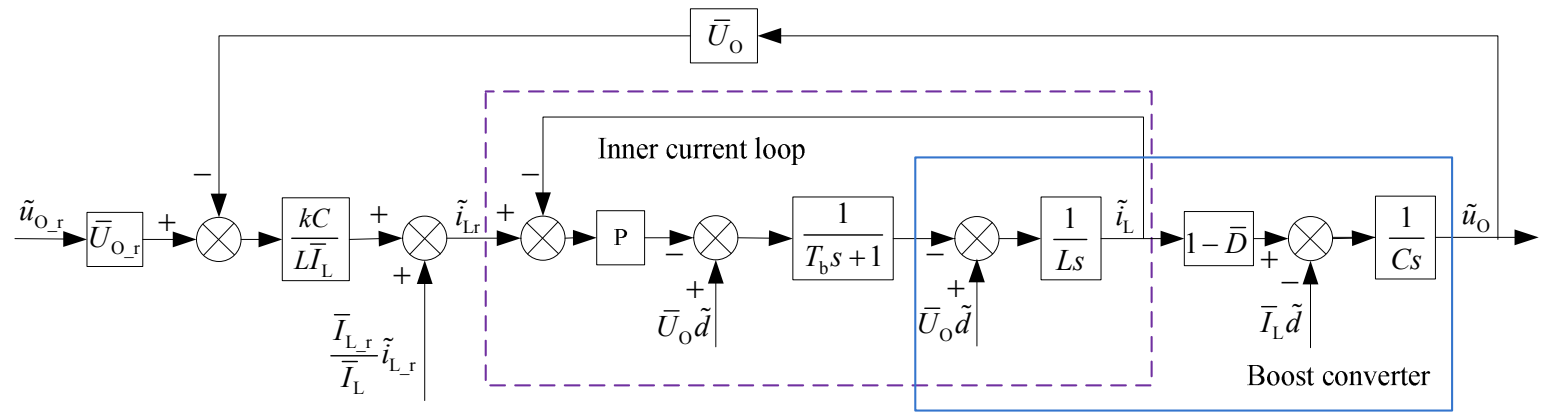

Fig. 5. Control diagram of small-signal mode.

which indicates that the energy in the circuit is always smaller than the target energy until the output voltage reaches the target.

When $u_{\mathrm{O}}>u_{\mathrm{O}_{-} \mathrm{r}}$, the energy is:

$$
E_{\mathrm{LC}}=\frac{1}{2} L i_{\mathrm{L}_{-} \mathrm{r}}^{2}+\frac{1}{2} C u_{\mathrm{O}_{-} \mathrm{r}}^{2}-\frac{1}{2}(1-k) C\left(u_{\mathrm{O}_{-} \mathrm{r}}^{2}-u_{\mathrm{O}}^{2}\right)>E_{\mathrm{LC}_{-} \mathrm{r}}
$$

which indicates that the energy in the circuit is always larger than the target energy until the output voltage reaches the target.

Therefore, from (3), the energy control low can be:

$$
i_{\mathrm{L}}=\sqrt{i_{\mathrm{L}_{-\mathrm{r}}}{ }^{2}+k \frac{C}{L}\left(u_{\mathrm{O}_{-} \mathrm{r}}^{2}-u_{\mathrm{O}}^{2}\right)}
$$

The control diagram is shown in Fig. 4, where the inside of the dashed box is the current loop and outside is the energy loop with the control law (6). Considering the control delay: $\frac{1}{T_{\mathrm{b}} s+1}$ is added.

In order to study the stability of the proposed control, the small-signal analysis method is employed as follows:

$$
\left\{\begin{array}{c}
u_{\mathrm{O}}=\bar{U}_{\mathrm{O}}+\tilde{u}_{\mathrm{O}} \\
u_{\mathrm{O}_{-} \mathrm{r}}=\bar{U}_{\mathrm{O}_{-} \mathrm{r}}+\tilde{u}_{\mathrm{O} \_\mathrm{r}} \\
i_{\mathrm{L}}=\bar{I}_{\mathrm{L}}+\tilde{i}_{\mathrm{L}} \\
i_{\mathrm{L}_{-} \mathrm{r}}=\bar{I}_{\mathrm{L}_{-} \mathrm{r}}+\tilde{i}_{\mathrm{L}_{-} \mathrm{r}} \\
d=\bar{D}+\tilde{d}
\end{array}\right.
$$

where $\bar{U}_{\mathrm{O}}, \bar{U}_{\mathrm{O}_{-} \mathrm{r}}, \bar{I}_{\mathrm{L}}, \bar{I}_{\mathrm{L}_{-} \mathrm{r}}$ and $\bar{D}$ donate large signals, and $\tilde{u}_{\mathrm{O}}, \tilde{u}_{\mathrm{O}_{\mathrm{r}}}, \tilde{i}_{\mathrm{L}}, \tilde{i}_{\mathrm{L}_{-} \mathrm{r}}$ and $\tilde{d}$ donate their corresponding small signals. The large signals constitute a stable operation point and the high order items of the small signals can be ignored in the small-signal analysis method. Thus, from (6) and (7), the small signal mode of the control law can be derived as:

$$
\tilde{i}_{\mathrm{L}}=\frac{\bar{I}_{\mathrm{L}_{\mathrm{r}} \mathrm{r}}}{\bar{I}_{\mathrm{L}}} \tilde{i}_{\mathrm{L}_{-} \mathrm{r}}+\frac{k C}{L \bar{I}_{\mathrm{L}}}\left(\bar{U}_{\mathrm{O}_{-}} \tilde{u}_{\mathrm{O}_{-} \mathrm{r}}-\bar{U}_{\mathrm{O}} \tilde{u}_{\mathrm{O}}\right)
$$

According to Fig. 5 which shows a control diagram of the small-signal mode based on (8), the closed-loop transfer function of the output voltage is:

$$
G(s)=\frac{\tilde{u}_{\mathrm{O}}}{\tilde{u}_{\mathrm{O}_{-} \mathrm{r}}}=\frac{\bar{U}_{\mathrm{O}_{-} \mathrm{r}} \frac{k C}{L \bar{I}_{\mathrm{L}}} P(1-\bar{D})}{C s\left[P+\left(T_{\mathrm{b}} s+1\right) L s\right]+\bar{U}_{\mathrm{O}} \frac{k C}{L \bar{I}_{\mathrm{L}}} P(1-\bar{D})}
$$

From (9), the locations of the poles of the system can be obtained as shown in Fig. 6. As can be seen, all of the poles are on the left side of the imaginary axis when $k$ changes from 0.1 to 1 , the inductor changes from $0.5 L$ to $1.5 \mathrm{~L}$, or the capacitor changes from $0.5 C$ to $1.5 C$. Therefore, the system is stable and has a good robustness.

\section{PERFormance OF THE ENERGy CONTROL}

According to (6), the maximum inductor current of the energy control is related to parameter $k$. The larger $k$ is, the larger the maximum inductor current becomes. Since the input power is proportional to the inductor current, the maximum input power depends on the maximum inductor current. The larger $k$ is, the larger the input power becomes, as shown in Fig. 7. As the energy changes $E_{1 \_\mathrm{k} 1}$ and $E_{2 \_\mathrm{k} 2}$ of different values of $k$ should be the same, the transition time $t_{4}-t_{1}$ of $k_{2}$ should be longer than the transition time $t_{3}-t_{1}$ of $k_{1}$. Moreover, if the 


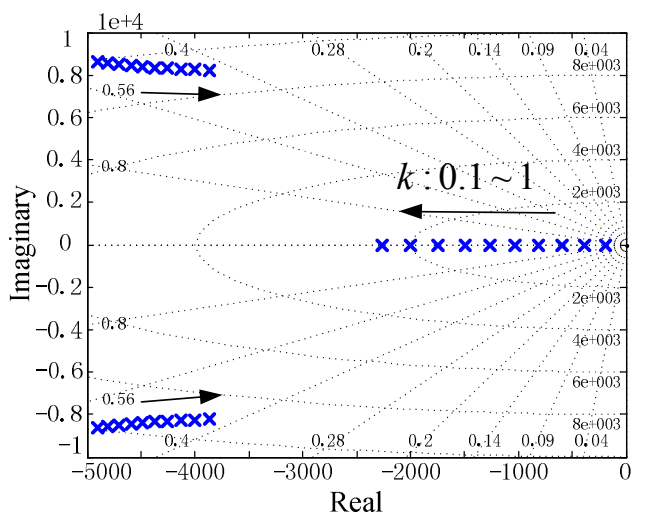

(a) $k: 0.1 \sim 1$.

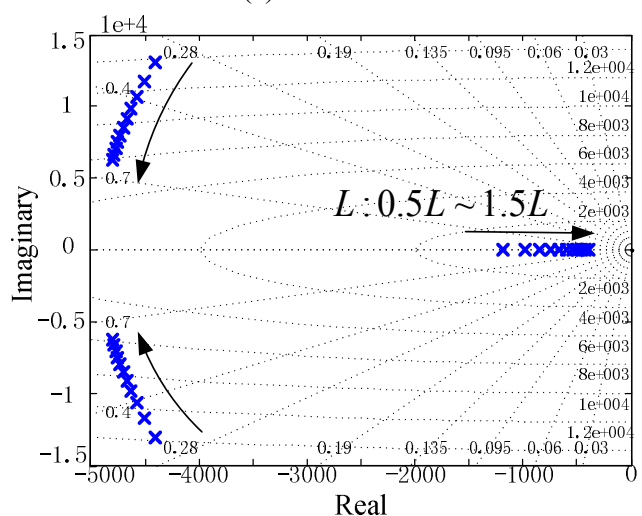

(b) $L: 0.5 L \sim 1.5 L$.

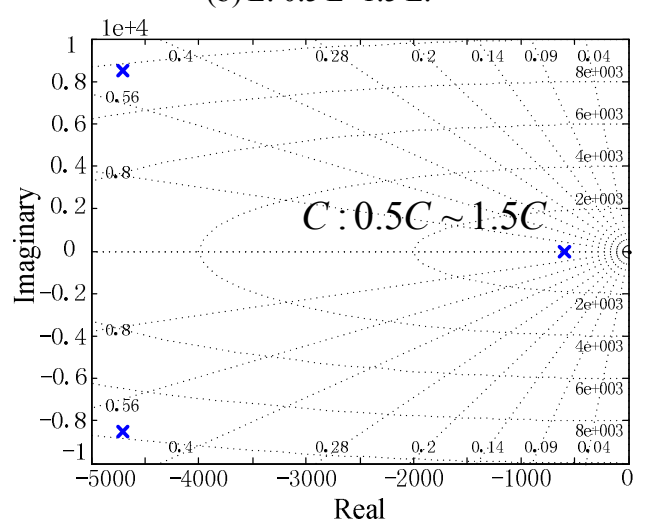

(c) $C: 0.5 C \sim 1.5 C$.

Fig. 6. Location of poles.

maximum inductor current is smaller, the voltage deviation which represents the energy loss of the capacitor can be smaller by energy balancing. Therefore, the control parameter $k$ is chosen to decide the trade off, while $0<k<1$. The larger $k$ is, the shorter the recovery time $t_{\mathrm{r}}$ becomes and the larger the output voltage deviation $\Delta u_{\mathrm{O}}$ becomes.

The performance of the proposed control with different values os $k$ will be investigated in the following. The parameters of the circuit are listed in Table I.

When the load resistance suddenly changes from $41.6 \Omega$ to $10.2 \Omega$, the trajectory of the time-optimal (TO) control and the different trajectories in the proposed control with different values of $t_{\mathrm{r}}$ are shown in Fig. 8.

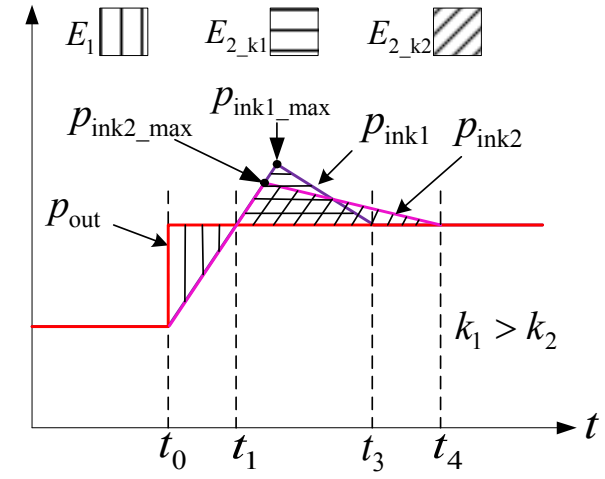

Fig. 7. The influence of $k$.

TABLE I

PARAMETERS OF CIRCUIT

\begin{tabular}{ll}
\hline \multicolumn{1}{c}{ Parameter } & \multicolumn{1}{c}{ Value } \\
\hline Input voltage $U_{\text {in }}$ & $30 \mathrm{~V}$ \\
Output voltage $u_{\mathrm{O}}$ & $70 \mathrm{~V}$ \\
Inductor $L$ & $1 \mathrm{mH}$ \\
Capacitor $C$ & $1000 \mathrm{uF}$ \\
Switch Frequency $f_{\mathrm{s}}$ & $10 \mathrm{kHz}$ \\
\hline
\end{tabular}

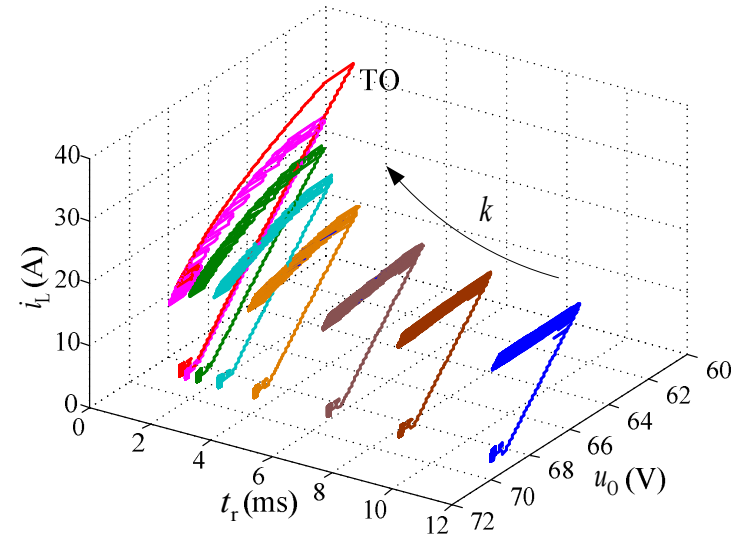

Fig. 8. Different trajectories and $t_{\mathrm{r}}$.

With an increase of $k$, the trajectory in the proposed control becomes closer to TO and $t_{\mathrm{r}}$ becomes smaller. Meanwhile the peak current of the inductor $i_{\text {Lmax }}$ and the output voltage deviation $\Delta u_{\mathrm{O}}$ both increase. The relationship between $\Delta u_{\mathrm{O}}, t_{\mathrm{r}}$ and $k$ is shown in Fig. 9. The relationship between $\Delta u_{\mathrm{O}}$ and $i_{\text {Lmax }}$ is shown in Fig. 10.

$\Delta u_{\mathrm{O}}$ and $t_{\mathrm{r}}$ are the both of interest. A comparison of PI control, synergetic control and the proposed control is shown in Fig. 11. Obviously, the proposed control can achieve a better dynamic performance, because the curve of the proposed control is under the curves of both the PI control and the synergetic control. With the same $t_{\mathrm{r}}, \Delta u_{\mathrm{O}}$ of the proposed control is smaller, especially when $t_{\mathrm{r}}$ is small.

Furthermore, the control parameter $k$ of the proposed control is easier to choose since it should always be larger than 0 and smaller than 1 for different systems. In order to reduce the 


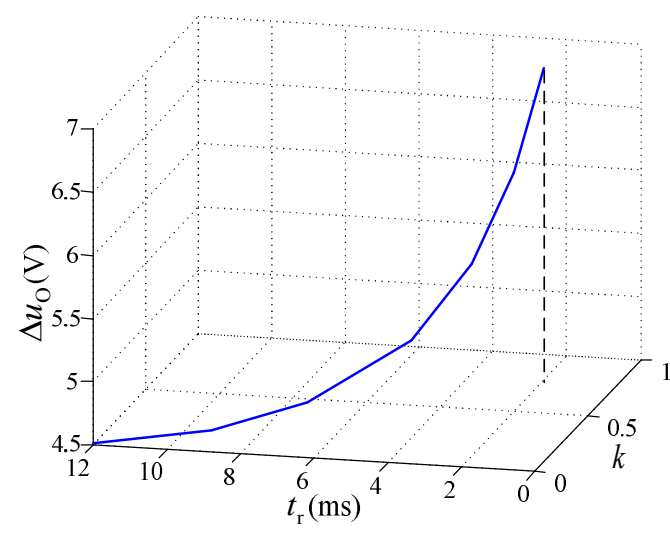

Fig. 9. The relation of $\Delta u_{\mathrm{O}}, t_{\mathrm{r}}$ and $k$.

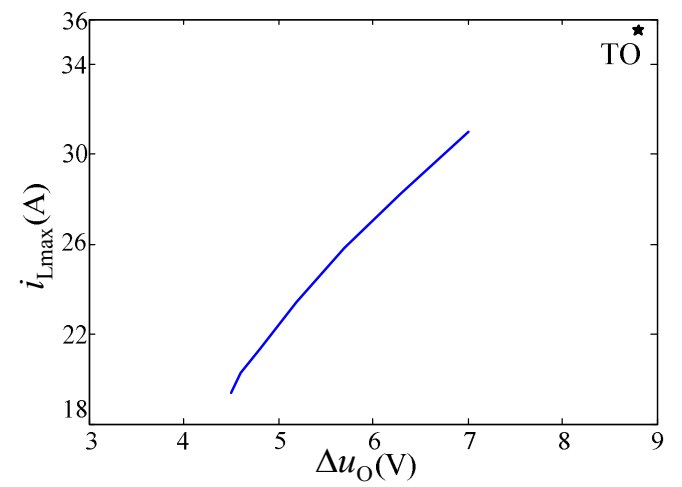

Fig. 10. The relation of $\Delta u_{\mathrm{O}}$ and $i_{\mathrm{Lmax}}$.

output voltage deviation with less time, the points before the inflection point where $t_{\mathrm{r}}$ is about $2.5 \mathrm{~ms}$, are better choices for the system in Table I. Thus, $k$ should be larger than 0.45 and smaller than 1 according to Fig. 11.

When the value of the inductor or the capacitor has an error of $\pm 10 \%$, the proposed control still can achieve nearly the same results with the exact parameters, as shown in Fig. 12. Thus, the proposed control is insensitive to the system parameters.

\section{EXPERIMENTAL RESULTS}

In order to confirm the correctness of the theoretical analysis and to verify the validity of the proposed energy control, a boost converter prototype of $500 \mathrm{~W}$ is established. A TMS320F28335 digital signal processor (DSP) which samples at $20 \mathrm{kHz}$ is utilized for the experiment. The parameters of the experimental circuit are the same as those in Table I.

An experimental comparison of the PI control, the synergetic control and the proposed control is shown in Fig. 13, which is in agreement with the simulation in Fig. 11. The proposed control shows the best performance.

The experimental waveforms of the time-optimal control are shown in Fig. 14. The load changes from $41.6 \Omega$ to $10.2 \Omega$ as well. In Fig. 14(a), the peak value of the inductor current is 37 A. The voltage deviation is $8.4 \mathrm{~V}$. The recovery time is $1.6 \mathrm{~ms}$,

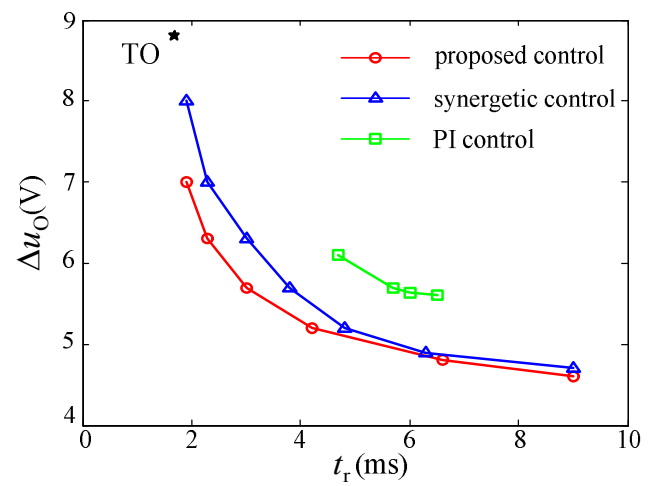

Fig. 11. The performances of PI control, synergetic control and the proposed control.

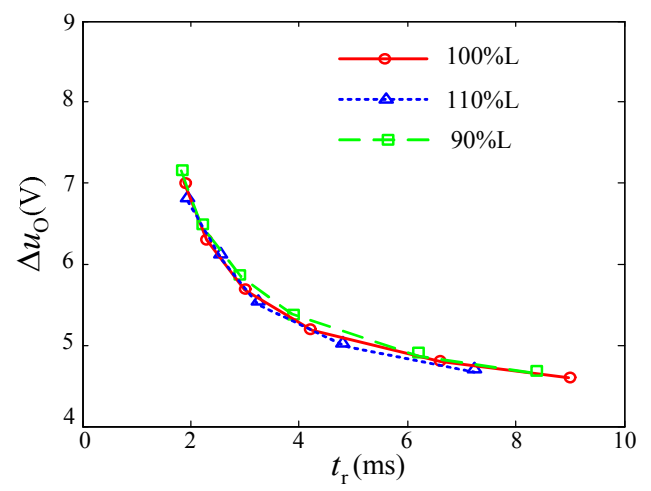

(a)

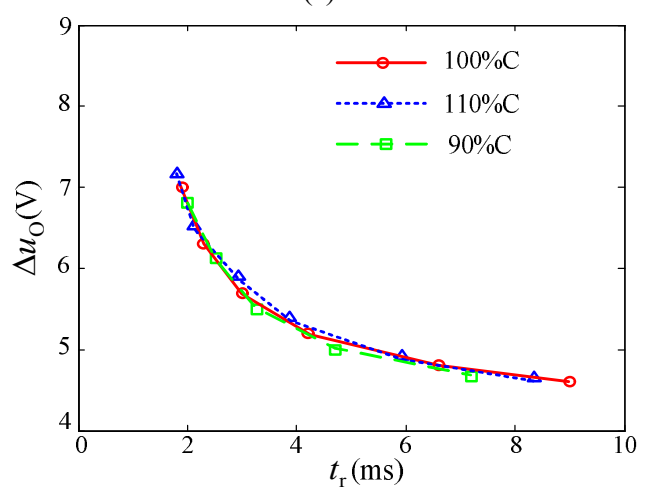

(b)

Fig. 12. Tolerance of $L$ and C. (a) $\pm 10 \%$ error of $L$. (b) $\pm 10 \%$ error of $C$.

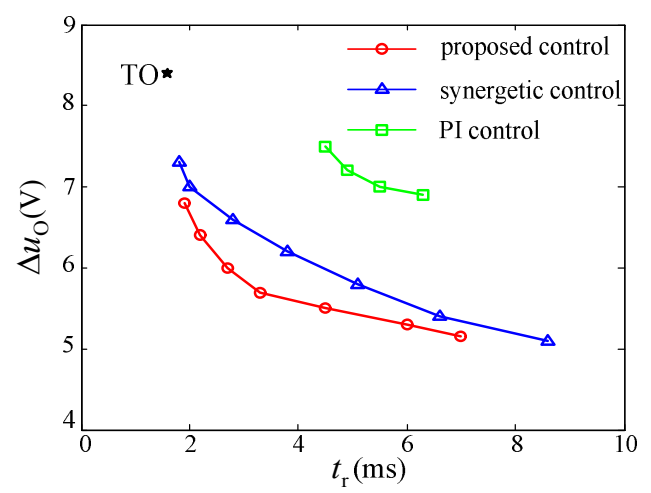

Fig. 13. Experimental results of PI control, synergetic control and the proposed control. 


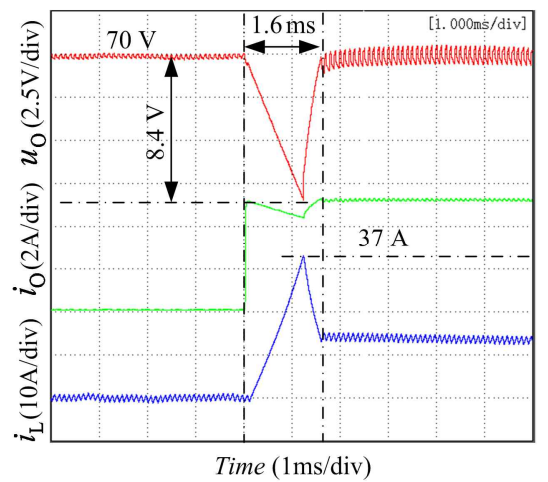

(a)

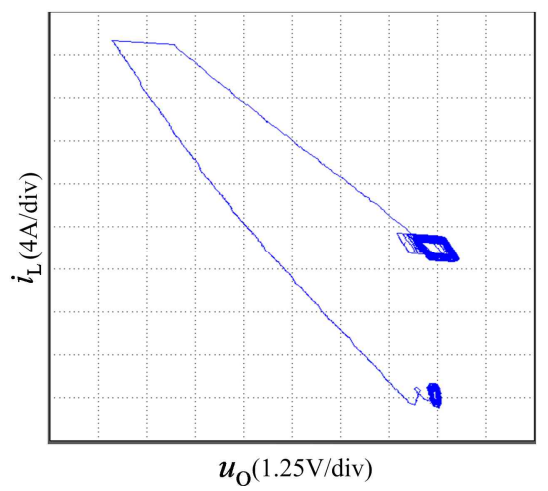

(b)

Fig. 14. Experimental results of time-optimal control. (a) Output voltage, output current and inductor current. (b) Phase plane.

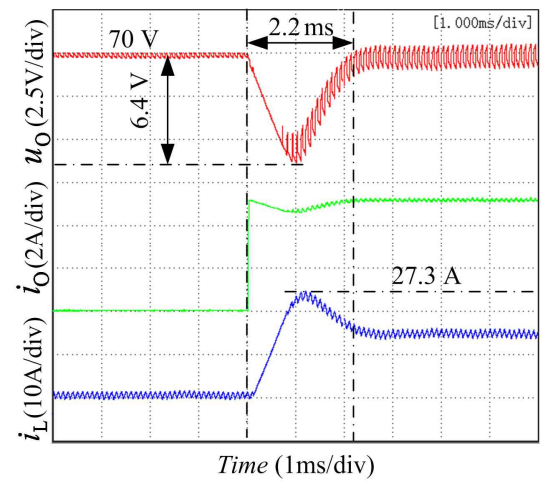

(a)

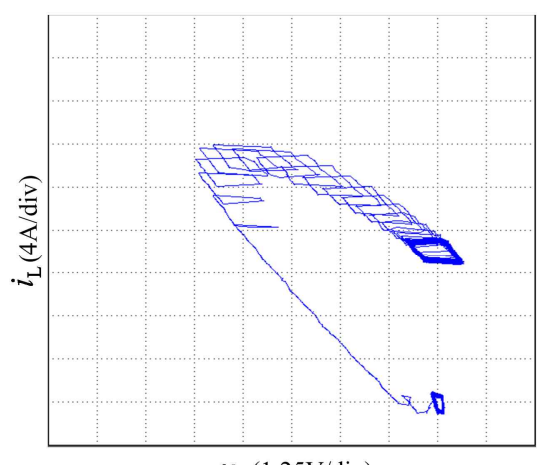

(b)

Fig. 15. Experimental results of proposed control. (a) Output voltage, output current and inductor current. (b) Phase plane.

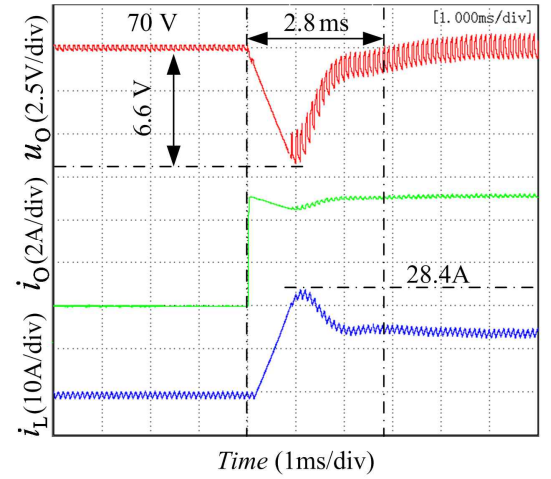

(a)

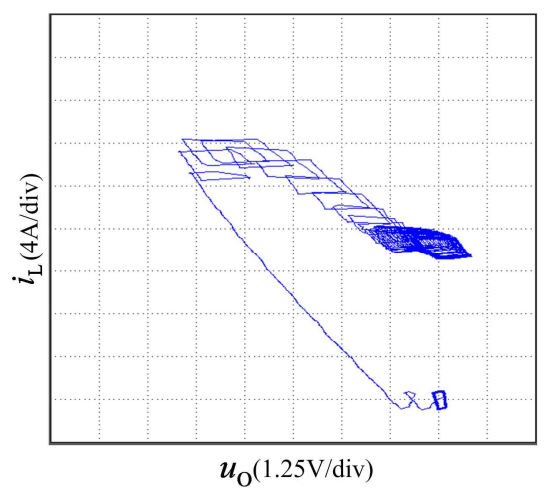

(b)

Fig. 16. Experimental results of synergetic control. (a) Output voltage, output current and inductor current. (b) Phase plane.

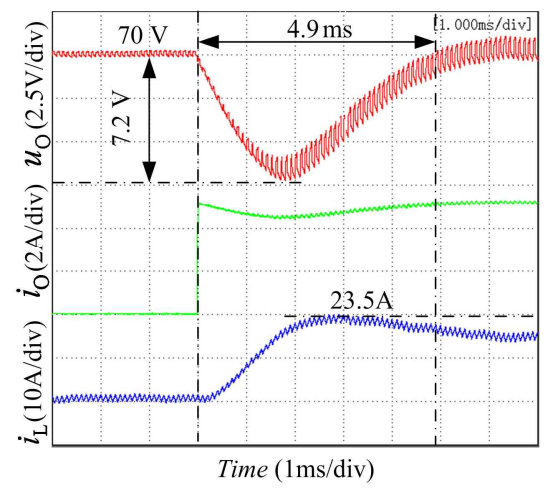

(a)

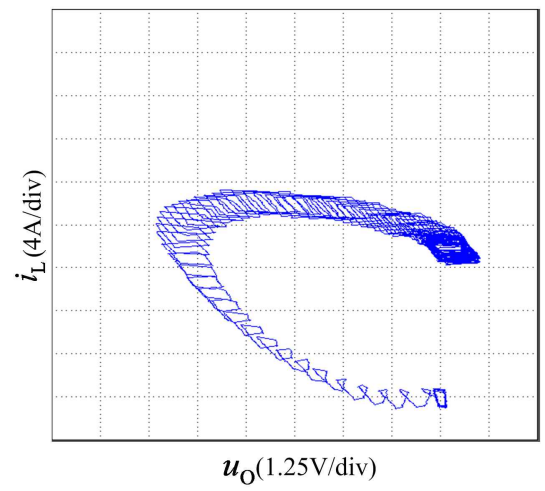

(b)

Fig. 17. Experimental results of PI control. (a) Output voltage, output current and inductor current. (b) Phase plane. 
which is the shortest time. Fig. 14(b) shows the phase plane curve, which indicates the relationship between the output voltage and the inductor current.

The experimental waveforms of the proposed control are shown in Fig. 15. The recovery time is $2.2 \mathrm{~ms}$, which is longer than the $1.6 \mathrm{~ms}$ in Fig. 14(a). However, the voltage deviation is $6.4 \mathrm{~V}$, which is much smaller than $8.4 \mathrm{~V}$. Moreover, its peak inductor current is smaller as well. When compared to the experimental waveforms of the synergetic control in Fig. 16, the recovery time and voltage deviation of the proposed control are both smaller than those of the synergetic control, i.e., 2.8 $\mathrm{ms}$ and $6.6 \mathrm{~V}$. However, both the proposed control and the synergetic control have much better performances than the PI control in Fig. 17, which agrees with the theoretical analysis. Therefore, a better tradeoff, i.e., a reducing output voltage deviation with less time, can be achieved by the proposed control. As can be seen, the phase plane curves of the different controls are quite different from each other. This implies that their energy changing processes are different.

\section{CONCLUSION}

The minimum output voltage deviation and the minimum recovery time cannot both be achieved at the same time for boost converters, so a good tradeoff between them is valuable. This paper proposes a novel energy control to modify the energy storage in the circuit. The performance of the proposed control whose control parameters are easy to choose is analyzed. The experimental results obtained from a $500 \mathrm{~W}$ prototype are in agreement with the theoretical analysis, and they show that the proposed control achieves a better tradeoff between the minimum output voltage deviation and the minimum recovery time.

\section{ACKNOWLEDGMENT}

The authors would like to thank the State Grid Corporation of China for the support of the project titled Research on the Energy Router in the Distribution Network for the Energy Internet.

\section{REFERENCES}

[1] R. Munzert and P. T. Krein, "Issues in boundary control," in Proc. IEEE Power Electronics Specialists Conference, pp. 810-816, 1996.

[2] M. Greuel, R. Muyshondt and P. T. Krein, "Design approaches to boundary controllers," in Proc. IEEE Power Electronics Specialists Conference, pp. 672-678, 1997.

[3] K. K. Leung and H. S. Chung, "A comparative study of boundary control with first- and second-order switching surfaces for buck converters operating in DCM," IEEE Trans. Power Electronics, Vol. 22, No. 4, pp. 1196-1209, Jul. 2007.

[4] W. Yan, C. N. Ho, H. S. Chung, and K. T. K. Au, "Fixed-frequency boundary control of buck converter with
Second-Order switching surface," IEEE Trans. Power Electron., Vol. 24, No. 9, pp. 2193-2201, Sep. 2009.

[5] K. K. S. Leung and H. S. H. Chung, "Derivation of a second-order switching surface in the boundary control of buck converters," IEEE Power Electron. Lett., Vol. 2, No. 2, pp. 63-67, Jun. 2004.

[6] M. Ordonez, M. T. Iqbal and J. E. Quaicoe, "Selection of a curved switching surface for buck converters," IEEE Trans. Power Electron., Vol. 21, No. 4, pp. 1148-1153, Jul. 2006.

[7] J. Galvez, M. Ordonez, F. Luchino and J. Quaicoe, "Improvements in boundary control of boost converters using the natural switching surface," IEEE Trans. Power Electron., Vol. 26, No. 11, pp. 3367-3376, Nov. 2011.

[8] G. E. Pitel and P. T. Krein, "Minimum-Time transient recovery for DC - DC converters using raster control surfaces," IEEE Trans. Power Electron., Vol. 24, No. 12, pp. 2692-2703, Dec. 2009.

[9] S. Kapat and P. T. Krein, "Improved time optimal control of a buck converter based on capacitor current," IEEE Trans. Power Electron., Vol. 27, No. 3, pp. 1444-1454, Mar. 2012.

[10] G. Feng, E. Meyer, and Y. Liu, "A new digital control algorithm to achieve optimal dynamic performance in DC-to-DC converters," IEEE Trans. Power Electron., Vol. 22, No. 4, pp. 1489-1498, Jul. 2007.

[11] O. Kumar, P. S. Shenoy, P. T. Krein, and S. Kapat, "Augmented boost converter for near null-load transient response," in Proc. IEEE Power and Energy Conference at Illinois (PECI) , pp. 1-6, 2011.

[12] S. Kapat, P. S. Shenoy and P. T. Krein, "Near-Null response to Large-Signal transients in an augmented buck converter: A geometric approach," IEEE Trans. Power Electron., Vol. 27, No. 7, pp. 3319-3329, Jul. 2012.

[13] T. Geyer, G. Papafotiou, R. Frasca, and M. Morari, "Constrained optimal control of the step-down DC-DC converter," IEEE Trans. Power Electron., Vol. 23, No. 5, pp. 2454-2464, Sep. 2008.

[14] L. Corradini, A. Babazadeh, A. Bjeletić, and D. Maksimović, "Current-limited time-optimal response in digitally controlled DC-DC converters," IEEE Trans. Power Electron., Vol. 25, No. 11, pp. 2869-2880, Nov. 2010.

[15] S. Banerjee and G. Verghese, Nonlinear phenomena in power electronics: Bifurcations, chaos, control, and applications, Wiley-IEEE Press, pp. 371-385, 2001.

[16] H. Komurcugil and O. Kukrer, "Lyapunov-based control for three-phase PWM AC/DC voltage-source converters," IEEE Trans. Power Electron., Vol. 13, No. 5, pp. 801-813, Sep. 1998.

[17] H. Komurcugil and O. Kukrer, "A new control strategy for Single-Phase shunt active power filters using a lyapunov function," IEEE Trans. Ind. Electron., Vol. 53, No. 1, pp. 305-312, Feb. 2006.

[18] C. Meza, D. Biel, D. Jeltsema, and J. M. A. Scherpen, "Lyapunov-Based control scheme for Single-Phase Grid-Connected PV central inverters," IEEE Trans. Contr. Syst. Technol., Vol. 20, No 2, pp. 520-529, Mar. 2012.

[19] R. Ortega, A. J. Van Der Schaft, I. Mareels, and B. Maschke, "Putting energy back in control," IEEE Contr. Syst., Vol. 21, No. 2, pp. 18-33, Apr. 2001.

[20] A. D. Aquila, M. Liserre, V. G. Monopoli, and P. Rotondo, "An energy-based control for an n-H-bridges multilevel active rectifier," IEEE Trans. Ind. Electron., Vol. 52, No. 3, pp. 670-678, Jun. 2005. 
[21] H. Komurcugil, "Steady-state analysis and passivity-based control of single-phase PWM current-source inverters," IEEE Trans. Ind. Electron., Vol. 57, No. 3, pp. 1026-1030, Mar. 2010

[22] L. Tzann-Shin, "Lagrangian modeling and passivity-based control of three-phase AC/DC voltage-source converters," IEEE Trans. Ind. Electron., Vol. 51, No. 4, pp. 892-902, Aug. 2004.

[23] Y.-I. Son and I.-H. Kim, "Complementary PID controller to Passivity-Based nonlinear control of boost converters with inductor resistance," IEEE Trans. Contr. Syst. Technol., Vol. 20, No. 3, pp. 826-834, May 2012.

[24] G. C. Konstantopoulos and A. T. Alexandridis, "Generalized nonlinear stabilizing controllers for Hamiltonian-Passive systems with switching devices," IEEE Trans. Contr. Syst. Technol., Vol. 21, No. 4, pp. 1479-1488, Jul. 2013.

[25] G. E. Valderrama, A. M. Stankovic and P. Mattavelli, "Dissipativity-based adaptive and robust control of ups in unbalanced operation," IEEE Trans. Power Electron., Vol. 18, No. 4, pp. 1056-1062, Jul. 2003.

[26] H. Sira-Ramirez and M. Rios-Bolivar, "Sliding mode control of DC-to-DC power converters via extended linearization," IEEE Trans. Circuits and Syst. I: Fundam. Theory and Appl., Vol. 41, No. 10, pp. 652-661, Oct. 1994.

[27] S. Tan, Y. M. Lai, C. K. Tse, L. Martinez-Salamero, and C. $\mathrm{Wu}$, "A Fast-Response Sliding-Mode controller for Boost-Type converters with a wide range of operating conditions," IEEE Trans. Ind. Electron., Vol. 54, No. 6, pp. 3276-3286, Dec. 2007.

[28] L. Martinez-Salamero, G. Garcia, M. Orellana, C. Lahore, and B. Estibals, "Start-up control and voltage regulation in a boost converter under Sliding-Mode operation," IEEE Trans. Ind. Electron., Vol. 60, No. 10, pp. 4637-4649, Oct. 2013.

[29] A. Kolesnikov, G. Veselov, A. Kolesnikov, A. Monti, F. Ponci, E. Santi, and R. Dougal, "Synergetic synthesis of DC-DC boost converter controllers: Theory and experimental analysis," in Proc. IEEE Applied Power Electronics Conference and Exposition (APEC), Vol. 1, pp. 409-415, 2002.

[30] E. Santi, A. Monti, D. Li, K. Proddutur, and R. A. Dougal, "Synergetic control for DC-DC boost converter: Implementation options," IEEE Trans. Industry Applications, Vol. 39, No. 6, pp. 1803-1813, Nov./Dec. 2003.

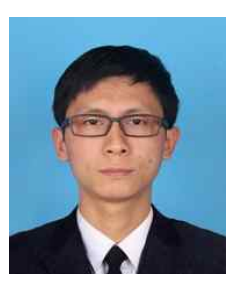

Junjie Ge was born in Hubei, China. He received his B.S. degree in Hydroelectric Power Engineering from the Huazhong University of Science and Technology, Wuhan, China, in 2010. He is presently working toward his Ph.D. degree in Electrical Engineering from Tsinghua University, Beijing, China. His current research interests include solid state transformers, active power filters and photovoltaic generation.

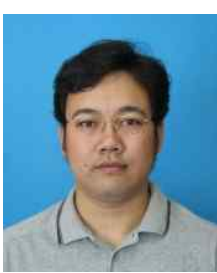

Liqiang Yuan received his B.S. and Ph.D. degrees from Tsinghua University, Beijing, China, in 1999 and 2004, respectively. He became an Assistant Professor, in 2004, and an Associate Professor, in 2008, in the Department of Electrical Engineering, Tsinghua University. His current research interests include the application techniques of semiconductor devices, photovoltaic systems, and high power high voltage converters.

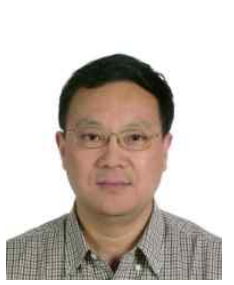

Zhengming Zhao received his B.S. and M.S. degrees in Electrical Engineering from Hunan University, Changsha, China, in 1982 and 1985, respectively. He received his Ph.D. degree from Tsinghua University, Beijing, China, in 1991, and then worked in the Department of Electrical Engineering, Tsinghua University. From 1994 to 1996, he was a Postdoctoral Fellow at Ohio State University, Columbus, $\mathrm{OH}$, USA. The following year, he worked as a Visiting Scholar at the University of California, Irvine, CA, USA. He is presently a Professor in Department of Electrical Engineering, Tsinghua University. He is also the Deputy Director of the State Key Lab of Power Systems, Vice President of the Beijing Power Electronic Society, Chairman of the IEEE PELS Beijing Chapter, and an IET Fellow. Dr. Zhao's current research interests include high power conversion, power electronics, motor control, and solar energy applications.

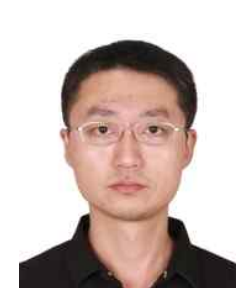

Ting Lu received his B.S. and Ph.D. degrees in Electrical Engineering from Tsinghua University, Beijing, China, in 2005 and 2010, respectively. From 2010 to 2012, he was a Postdoctoral Fellow with the Department of Electrical Engineering, Tsinghua University. Since 2012, he has been an Assistant Professor in the Department of Electrical Engineering, Tsinghua University. His current research interests include the application techniques of high power semiconductor devices and the control strategies of high power high voltage converters.

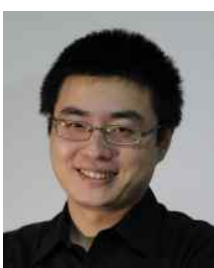

Fanbo He received his B.S. and Ph.D. degrees in Electrical Engineering from Tsinghua University, Beijing, China, in 2007 and 2012, respectively. Since 2012, he has been a Postdoctoral Fellow in the Department of Electrical Engineering, Tsinghua University. His current research interests include the application techniques of semiconductor devices and photovoltaic systems.

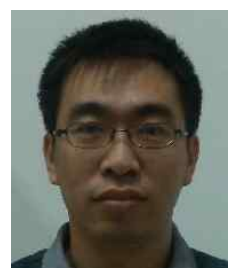

Gaohui Feng received his B.S. and M.S. degrees from the Mechanical Engineering College, Shijiazhuang, China, in 2002 and 2005 , respectively. He is presently working toward his Ph.D. degree at the State Key Laboratory of Control and Simulation of Power System and Generation Equipment, Department of Electrical Engineering, Tsinghua University, Beijing, China. His current research interests include high-voltage and high-power converter designs, and digital control techniques. 